\title{
Pop-Rock Music: Aesthetic Cosmopolitanism in Late Modernity
}

\author{
Motti Regev \\ Cambridge: Polity Press, 2013 \\ ISBN 978-0-7456-6173-5
}

\author{
Brett Wilson \\ Vision College School of Music \\ brett.w@visioncollege.ac.nz
}

This book highlights the connecting threads between contemporary sociological theory and the nebulous fusion of pop music and rock music that is "pop-rock". The author, Motti Regev, addresses three questions: why did pop-rock emerge to become such a prominent cultural form on a world scale? How did pop-rock music achieve its status and legitimacy? And what are the cultural consequences of this achievement?

The first example given, the popular Japanese song "Ruju", initially appears incongruous with the questions above, particularly in relation to notions of pop-rock's status and legitimacy. Regev maintains that "Ruju" exemplifies the aesthetic idiom of pop-rock music. While it is essentially a pop song, it is suggested that the incorporation of a rock guitar solo blurs the boundaries of pop and rock, placing it in the pop-rock category. Initially, this suggests a misjudgement that any inclusion of a rock signifier in a pop song automatically qualifies as legitimate pop-rock. A token reference to any genre outside of that to which the song belongs, could just as easily come across as pastiche or kitsch. However, it becomes clear that the author uses the pop-rock label as one that covers a multitude of popular music sub-genres (ranging from disco to extreme heavy metal) on the basis that not only are they produced via amplification and electronic instruments, but also that the aesthetics are hybrid, reflecting multiple cultures. It is suggested that the latter notion disqualifies pop-rock from falling under the broader term of popular music.

Semantics aside, the book primarily focuses on pop-rock to illustrate aesthetic cosmopolitanism, that is, world culture as an interconnected entity. This necessitates a survey of pop-rock of differing cultures rather than Anglo-American pop-rock exclusively. And it is here that Regev thoroughly, though not exhaustively, discusses pop-rock from many parts of the globe as well as the music's isomorphic nature due to the aesthetic similarities, yet, differing cultural backgrounds.

Differing audiences of heavy metal in Indonesia serve as case-study in aesthetic cultures: Balinese metal enthusiasts demonstrate an ardent fan base or subculture, whereas Jakartans reveal a more casual response, perhaps due to wider taste 
preferences. Included in this is a discussion on "pop-rock knowledge" (131) and how the Internet has greatly affected this. Pop-rock knowledge is broken down to two categories: a database type of knowledge or "discursive knowledge" (such as, learning the band names and musicians, knowing the album titles) and a more participatory based knowledge, or "experiential knowledge" (for example, listening to and "owning" the music). It is espoused that pre-Internet, the first category may have been easier to take part in than the second, particularly with those fans who were physically well-removed from the country of the artist(s) origin.

What follows is an obvious, but necessary observation of how Internet platforms have played a major role in increasing participation of aesthetic cultures of pop-rock via streaming, downloading, peer-to-peer file sharing and/or immediate discussions on web forums with fellow fans across the world. Regev says of the Internet's impact: "Affording fans unhindered intensive engagement with almost endless amounts of local and global music, participation in aesthetic cultures of pop-rock have become a full-fledged materialization of aesthetic cosmopolitanism" (137). While this is no doubt true, it is questionable as to whether or not music listeners have become more engaged with music of differing cultures; the "intensive engagement" with local and global music perhaps remains within the confines of music typical to their culture.

While many case studies of differing aesthetic cultures are provided (particularly Israel in one chapter), it is the cumulative effect of aesthetic cultures in pop-rock that Regev suggests is vital to aesthetic cosmopolitanism. While he asserts that pop-rock has "brought formerly distant and separate cultural spaces into greater proximity" (178), it is perhaps a stretch to suggest it can serve as a tool to shape world culture as a single interconnected entity. Nevertheless, this book will open further discussion on the impact of pop-rock, both locally and globally. 